\title{
Comunicação cidadã na Amazônia brasileira: em defesa das atingidas e dos atingidos pela Vale S.A
}

Citizen communication in the Brazilian Amazon: in defense of those affected and affected by Vale S.A

Comunicación ciudadana en la Amazonia brasileña: en defensa de las afectadas y de los afectados por la Vale S.A

Larissa PEREIRA SANTOS, Brasil

Universidade Federal do Para / larissasantos.jornalista@gmail.com

Célia Regina Trindade CHAGAS AMORIM, Brasil

Universidade Federal do Para / celia.trindade.amorim@gmail.com

Chasqui. Revista Latinoamericana de Comunicación

N. ${ }^{\circ}$ 140, abril - julio 2019 (Sección Monográfico, pp. 179-194)

ISSN 1390-1079 / e-ISSN 1390-924X

Ecuador: CIESPAL

Recibido: 01-03-2019/Aprobado:08-05-2019 


\title{
Resumo
}

Este artigo centraliza as reflexões no âmbito da comunicação cidadã de movimentos sociais e organizações que trabalham em comunidades atingidas pela Vale S.A na Amazônia brasileira. Para isso, realizamos uma investigação teórico-metodológica da RedeJustiça nos Trilhos e seus processos comunicativos como ações importantes para o empoderamento de comunidades atingidas pela Vale S.A., nos estados do Pará e Maranhão, afetando a vida de mais de 100 comunidades brasileiras. A metodologia do artigo é de base qualitativa, e as contribuições teóricas de Freire (1983), Peruzzo (2005, 2009), Wolton (2010) e outros nos ajudam a reforçar a comunicação com um processo de interação social. Consideramos que a Rede Justiça nos Trilhos atua com a comunicação cidadã na perspectiva de empoderar os sujeitos para o reconhecimento e a defesa de direitos, para gerar transformações e agregar relações entre diferentes atores sociais.

Palabras chave: Comunicação e Cidadania; Comunidades; Amazônia; Rede Justiça nos Trilhos; Vale S.A.

\begin{abstract}
This article focuses the reflections on citizen communication of social movements and organizations that work in communities affected by Vale S.A in the Brazilian Amazon. For this, we carried out a theoretical-methodological investigation of the Justiça nos Trilhos and its communicative processes as important actions for the empowerment of communities affected by Vale S.A., in the states of Pará and Maranhão, affecting the lives of more than 100 Brazilian communities. The methodology of the article is qualitative, and the theoretical contributions of Freire (1983), Peruzzo (2005, 2009), Wolton (2010) and others help us to reinforce communication with a process of social interaction. We believe that the Justiça nos Trilhos works with citizen communication in the perspective of empowering individuals to recognize and defend rights, to generate transformations and to aggregate relationships among different social actors.
\end{abstract}

Keywords: Communication and Citizenship; Communities; Amazônia; Justiça nos Trilhos; Vale S.A.

\section{Resumen}

Este artículo centralizalas reflexiones en elámbito dela comunicación ciudadana de movimientos sociales y organizaciones que trabajan en comunidades afectadas por la Vale S.A en la Amazonia brasileña. Realizamos una investigación teórico-metodológica de la Red Justiça nos Trilhos y sus procesos comunicativos como acciones importantes para el empoderamiento de comunidades afectadas por la Vale S.A., en los estados de Pará y Maranhão, afectando la vida de más de 100 comunidades brasileñas. La metodología del artículo es de base cualitativa, y las contribuciones teóricas de Freire (1983), Peruzzo (2005, 2009), Wolton (2010) 
y otros nos ayudan a reforzar la comunicación como un proceso de interacción social. Consideramos que la Red Justiça nos Trilhos actúa con la comunicación ciudadana en la perspectiva de empoderar a los sujetos para el reconocimiento y la defensa de derechos, para generar transformaciones y agregar relaciones entre diferentes actores sociales.

Palavras-clave: Comunicación y Ciudadanía; Comunidades; Amazonia; Red Justiça nos Trilhos; Vale S.A.

\section{Introdução}

Partimos do pressuposto de que a comunicação é um processo de interação social e dialógico capaz de gerar transformação social. A partir dessa perspectiva crítico-reflexiva, localizamos a Rede Justiça nos Trilhos no âmbito da comunicação cidadã, como uma rede capaz de contribuir com o empoderamento de comunidades em torno da defesa de seus direitos que são afetados pela mineradora Vale S.A.

A Rede Justiça nos Trilhos surgiu durante o ano de 2007 em decorrência dos impactos negativos provocados por uma das maiores mineradoras do mundo: a Vale S.A. A presença da Vale S.A. na Amazônia brasileira, em outras regiões do Brasil e em outros países sempre foi permeada pelo discurso desenvolvimentista. Um discurso que desde a fundação da mineradora, em 1943, esconde uma série de violações de direitos vivenciadas por comunidades tradicionais, centros urbanos, camponeses, indígenas e quilombolas. $\mathrm{O}$ exemplo mais recente desse cenário negativo foi o rompimento de uma barragem de rejeitos de minério de ferro no estado de Minas Gerais, no Brasil. O segundo rompimento de barragem provocado no mesmo estado dentro de um período de três anos. Ambos contaram com a ausência de responsabilidade da mineradora Vale S.A. e o cumprimento de medidas de proteção ao meio ambiente e às pessoas.

Atualmente a Justiça nos Trilhos é uma das principais redes de comunidades e movimentos que tem atuação direcionada para o combate à violações de direitos humanos cometidos no âmbito das atividades de exploração mineral, especificamente pela Vale S.A. no Brasil. A Rede faz parte do contexto de surgimento dos novos movimentos que se organizam nas ruas e na internet para a promoção da cidadania. Segundo Castells (2015) "ao mesmo tempo, atores sociais e cidadãos individuais ao redor do mundo estão usando a nova capacidade de comunicação em rede para promover seus projetos, defender seus interesses e afirmar seus valores" (2015, p.104).

Diante disso, o objetivo deste artigo é refletir sobre a importância da comunicação cidadã da Rede Justiça nos Trilhos em defesa de comunidades 
atingidas pela Vale S.A., e na promoção de ações de cidadania nos estados do Maranhão e Pará.

\section{Comunicação e movimentos sociais}

Tendo em vista a organização da Rede Justiça nos Trilhos como sendo uma articulação comunicativa de comunidades e movimentos sociais que atua na Amazônia brasileira, destacamos um panorama de contribuições teóricas sobre os movimentos sociais e suas transformações na sociedade, bem como suas relações com práticas comunicativas.

Historicamente os movimentos sociais fazem parte das mudanças sociais e dos principais contextos de lutas e resistências. Mas cabe destacar que a partir da década de 1970, por ser um período no qual muitas ações sociopolíticas e tecnológicas aconteceram, há uma exigência de reavaliação teórica na área com novas categorizações (Melucci, 1989). Na Europa, o autor vai destacar que:

Autores como Touraine $(1973,1978)$ ou Habermas (1976) basearam suas análises numa abordagem "estrutural", sistêmica, que atribuía as novas formas de conflitos e a formação de novos atores (além das lutas tradicionais na força de trabalho) às mudanças no capitalismo pós-industrial. (Melucci, 1989, p. 50).

Melucci (1989) destaca que o movimento social é uma das questões mais indefiníveis, esclarecendo que seus estudos sobre o tema têm a função de fazer diferenciações e não de demarcar conceitos. Melucci analisa a atuação dos movimentos sociais como "sistemas de ação que operam num campo sistêmico de possibilidades e limites [...]." (Melucci, 1989, p. 52). Nesse sentido, o autor buscou entender as relações sociais de forma mais abrangente, os conflitos sociais que podem ser analisados dentro dessas relações e as interações entre os sujeitos. "Estudar os movimentos sociais significou para mim questionar a teoria social e lidar com questões epistemológicas tais como: o que é a ação social?" (Melucci apud Avritzer \& Lyyra, 1994, p. 155).

Alain Touraine (1989) descreve esse cenário de transformações políticas e tecnológicas como "sociedade pós-industrial", na qual as mobilizações passaram a ocorrer de forma cada vez mais generalizada. Com o desenvolvimento das comunicações e da informação, as relações entre as pessoas na sociedade se modificaram. Nesse sentido, aproximando-se de Melucci, Touraine (1989) reforça a característica da ação coletiva dos movimentos e o enfraquecimento da mediação dos partidos políticos.

A ideia, difundida pelo leninismo e de maneira muito mais extrema pela maioria dos movimentos nacionalistas e revolucionários do Terceiro Mundo, de que as reivindicações sociais precisam ser assumidas por um partido político para saírem da dependência em que se encontram parece já muito em atraso com relação à prática das sociedades industrializadas (Touraine, 1989, p. 8). 
O sentido de coletividade dos movimentos é apresentado pelos autores como uma forma de mobilização frente aos conflitos sociais. Alain Touraine (1989) diz que as reivindicações passam a ser definidas em nome da existência de uma coletividade e não se limitam a um único papel social. Ou seja, o movimento social vai além da função de ser um agente de pressão política. A ideia de um sujeito coletivo, que não se limita mais a um poder político, é transformada historicamente pela atuação de um sujeito que busca afirmar direitos, conquistar a igualdade e a liberdade, independentemente de partido político ou de orientação religiosa.

Na América Latina, nos anos 70 do século passado, a construção de um paradigma sobre os movimentos sociais envolve uma série de fatores apontados por Gohn, (2014, p. 227): a diversidade de movimentos sociais; a hegemonia sobre outros tipos de movimentos; o surgimento de novos movimentos sociais; o destaque internacional dos movimentos populares; as ações da Igreja Católica em relação aos movimentos; a problemática dos imigrantes; a questão indígena como fonte de conflito; a questão do preconceito racial; a relação entre movimentos sociais e o Estado; a falta de integração social; a institucionalização de conflitos; a ideologia; a função dos partidos políticos; a criação de temáticas; a categoria dos intelectuais; a problemática das classes sociais; as articulações entre diferentes lutas; a questão agrária; as estratégias e táticas dos movimentos; a heterogeneidade; a especificidade; e a atuação de Organizações Não Governamentais.

Observando as contribuições da autora, para além de querer elaborar um conceito, é importante construir, entre outras questões, uma reflexão teórica apontando as diferenças entre movimentos sociais e outros grupos de interesse, modos de ação coletiva e ONGs.

Por sua vez, Boaventura de Sousa Santos (2013, p. 252), reforça o debate ao observar que é complexo localizarmos em um conceito e uma teoria sociológica únicos a diversidade dos novos movimentos sociais das últimas décadas. Para 0 professor, a maior novidade dos novos movimentos sociais está na possibilidade de que eles "constituem tanto uma crítica da regulação social capitalista como uma crítica da emancipação social socialista tal como ela foi definida pelo marxismo." (2013 p. 253). E nesse sentido, Santos afirma que:

Ao identificar novas formas de opressão que extravasam das relações de produção e nem se quer são específicas delas, como sejam a guerra, a poluição, o machismo, o racismo ou o produtivismo, e ao advogar um novo paradigma social menos assente na riqueza e no bem-estar material da cultura e na qualidade de vida, os NVMs denunciam, com uma racionalidade sem precedentes, os excessos de regulação da modernidade (Santos, 2013, p. 253-254).

Nesse sentido, ao acompanharmos tais discussões teóricas importantes para as reflexões deste artigo, não situamos a Rede Justiça nos Trilhos dentro de uma denominação fechada de movimento social, a entendemos no processo 
de envolvimento e articulação de resistência com diversos movimentos e comunidades, ou nas palavras de Boaventura de Sousa Santos: "testemunhos de emergência de novos protagonismos num renovado espectro de inovação e transformações sociais" (2013, p.251).

O próprio nascimento da Justiça nos Trilhos, ainda como uma campanha internacional indica a identificação e adesão de movimentos sociais já existentes e envolvidos com as temáticas da mineração que passaram a ser enfrentadas pela Rede. E, nessas articulações a comunicação se tornou estratégica para ampliar direitos e dar visibilidade a demandas da comunidade, bem como uma forma de gerar relações com movimentos e outros atores em escala global.

De acordo com Castells (2013, p. 162), "indivíduos entusiasmados, conectados em rede", podem superar o medo e juntos lutar para fazer a mudança social. Assim, eles passam a agir de forma coletiva e consciente no enfrentamento dos problemas". Segundo o autor, esses processos também são desencadeados por ações comunicativas. Ele cita o exemplo das articulações em rede que podem ser observadas entre os movimentos sociais.

São conectados em rede de múltiplas formas. O uso das redes de comunicação da internet e dos telefones celulares é essencial, mas a forma de conectar-se em rede é multimodal. Inclui redes sociais on-line e off-line, assim como redes preexistentes e outras formadas durante as ações do movimento. As tecnologias que possibilitam a constituição de redes são significativas por fornecer a plataforma para essa prática continuada e que tende a se expandir, evoluindo com a mudança de formato do movimento (Castells, 2013, p. 164).

Assim como Castells, Paulo Freire (1983), também nos ajuda a entender a comunicação como uma possibilidade de transformação social com base em práticas cidadãs. As ideias de Freire têm como cerne a transformação e a emancipação dos sujeitos em contextos de injustiças e explorações. Essa característica pode ser identificada nos discursos e práticas da Rede Justiça nos Trilhos que tem como missão "fortalecer as comunidades ao longo do Corredor Carajás e denunciar as violações aos direitos humanos e da natureza responsabilizando Vale e Estado, prevenindo novas violações e reafirmando os modos de vida e a autonomia das comunidades nos seus territórios" (Justiça nos Trilhos, 2018).

A comunicação é então uma forma de relação, de existência, de estar no mundo. Com isso, podemos compreender as formas de denúncias e manifestações da Rede Justiça nos Trilhos como processos comunicacionais que buscam a afirmação de modos de vidas, de direitos e de sobrevivência. No site da Rede é possível identificar essa afirmação de modos de vidas e busca por direitos por meio das informações divulgadas no menu "comunidades" (Figura 1), que relata as dificuldades, impactos e resistências de diferentes territórios que são acompanhados pela Justiça nos Trilhos. 
Figura 1 - Página no site da Rede Justiça nos Trilhos em 08 set. 2018.

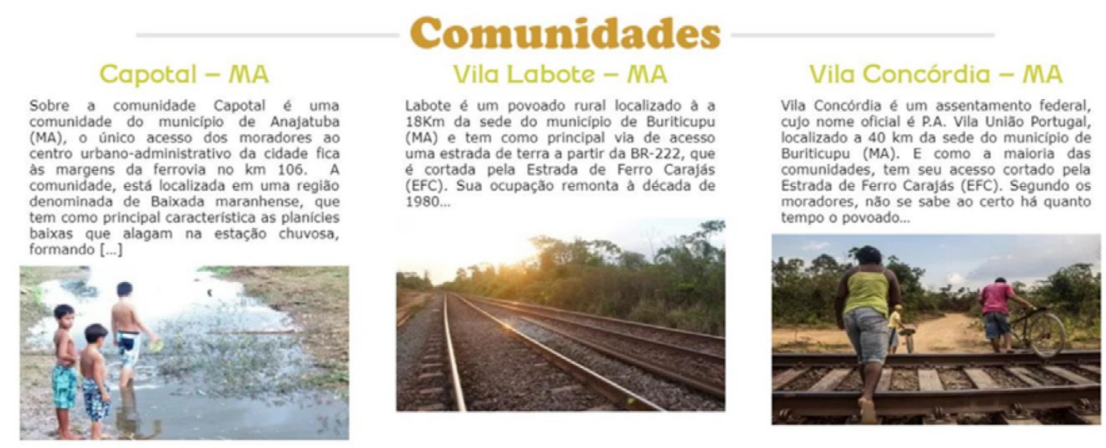

Fonte: Justiça nos Trilhos, 2017a.

Ao analisar o papel da comunicação no contexto dos movimentos populares, Cicília Peruzzo (2005) cita as seguintes características: uso dos meios de comunicação a serviço dos interesses da população; novas fontes de informação; comunicação como processo de mobilização social; abertura para a participação ativa do cidadão; dentre outras. Podemos observar essas características presentes nas articulações da Rede Justiça nos Trilhos, pois trata-se de um ator que consegue divulgar assuntos relacionados aos contextos das populações atingidas pela Vale S.A. e de suas regiões nacional e internacionalmente.

Identificamos também o site da Justiça nos Trilhos e as suas redes sociais na internet como "novas fontes de informação", capazes de denunciar assuntos que não são pautados na imprensa tradicional. São processos comunicacionais que buscam a emancipação dos sujeitos enquanto pessoas que têm demandas e interesses, questionamentos e opiniões para serem ouvidos e debatidos. Os pressupostos da cidadania, da educação e da contra-hegemonia ajudam a construir esses processos que ora são marginalizados, ora são criminalizados.

Portanto, as características apontadas por Peruzzo (2005), tão presentes em diversos movimentos sociais egrupos coletivos, sãoimportantes para refletirmos sobre o papel dos atores envolvidos nos movimentos como promotores de ações comunicativas que buscam ampliam práticas decidadania.

\section{Comunidades: espaços de construção da cidadania}

Pinsky e Pinsky (2013) abordam a cidadania como um processo que tem início com o estabelecimento de lutas e ideais e se modifica de acordo com os contextos políticos e culturais. Diz respeito, também, aos modos como os sujeitos se posicionam na busca por direitos. Os autores (2013) fazem um panorama sobre a cidadania em várias partes do mundo e esclarecem que no Brasil, a luta pela cidadania percorre contextos caracterizados por embates e mortes de pessoas. 
Mouffe (2003) reforça a importância de entender a natureza da cidadania a partir de uma perspectiva "agonística". Neste caso, ela defende uma ideia de democracia radical que pode se estabelecer na sociedade mediante a criação de espaços que permitama confrontação, a discussão, oembate político, entendendo o outro como adversário e não como inimigo. Assim, deve-se considerar que as ideias do outro podem e devem ser confrontadas, mas o direito do outro expor tais ideias não deve ser apagado. Nesse processo há possibilidades de debates que ajudam a exercitar a noção de cidadania.

A autora (2015) explica que "o reconhecimento da dimensão conflituosa da vida social” é uma das condições necessárias para compreender o papel da política democrática. Para ela a tarefa da política democrática não é ter o consenso como objetivo central na superação das dicotomias entre os diferentes grupos sociais, mas "elaborá-las de uma forma que estimule o confronto democrático” (Mouffe, 2015, p.15).

O caráter conflituoso pontuado por Mouffe (2015) pode ser observado nas sociedades contemporâneas também por meio da comunicação. No caso específico dos nossos estudos, os conflitos existentes entre a mineradora Vale S.A. e comunidades atingidas desmistifica a possibilidade de uma sociedade sem adversários, sem embates, sem confrontos.

O discurso oficial da mineradora Vale S.A., que apresenta a empresa como próxima das populações afetadas, em "diálogo" e no exercício de ações "sustentáveis", é contraposto pelas diversas comunidades e movimentos. Essas últimas encontram nas suas relações comunicativas oportunidades de denúncias. Neste caso incluímos a Rede Justiça nos Trilhos.

Ao pontuarmos a característica dos sujeitos que fazem a Rede como uma articulação comunicativa de comunidades, movimentos sociais, entidades, sindicatos, organizações, pesquisadores, dentre outros, destacamos também a sua essência comunitária, tendo em vista que a base de suas formas de organizações acontece nos territórios, com diferentes grupos sociais e em busca da realização dos desejos desses. Posteriormente, essas organizações se ampliam por meio de diálogos e estratégias comunicacionais na internet e em redes de encontros nacionais e internacionais.

Nos estados do Maranhão e Pará, pertencentes à Amazônia brasileira existem 27 municípios que são cortados pela Estrada de Ferro Carajás (EFC) e que são atingidas pela exploração mineral. A estrada é de concessão da mineradora Vale S.A., usada para o transporte e escoamento de minérios, grãos e gás. Para o uso das populações que vivem ao longo da linha férrea há um trem de passageiros. Ao longo do percurso que afeta esses estados existem mais de 100 comunidades que têm seus direitos violados. Por isso são assessoradas pela Rede Justiça nos Trilhos.

São comunidades que se identificam como ribeirinhas, pescadores, quilombolas, indígenas, camponeses, assentados, etc. Muitas estão envolvidas em redes de movimentos sociais e fazem parte da Justiça nos Trilhos. Além 
dessas populações, que em sua maioria localizam-se em áreas rurais, a EFC atinge centros urbanos e distritos industriais. Destacamos também os próprios movimentos sociais a partir de uma concepção de comunidade, com base nas suas relações e formas de organizações na sociedade.

Cada uma dessas comunidades apresenta modos de vida, formas de resistências e de lutas contra os impactos da mineração, elas congregam semelhanças e afinidades. Mas esse ambiente também é permeado por tensões, conflitos, diferenças e por um intenso processo de busca por cidadania, já que são comunidades que se reconhecem enquanto atingidas e lutam por direitos. Essas são características citadas por Peruzzo (2009) como estruturantes para o sentido de comunidade.

O sentimento de pertença, a participação, a conjunção de interesses e a interação, por exemplo, são características que persistem ao longo da história, enquanto a noção de lócus territorial específico como elemento estruturante de comunidade está superada pelas alterações provocadas pela incorporação de novas tecnologias da informação e comunicação. Sem menosprezar que a questão do espaço geográfico continua sendo um importante fator de agregação social em determinados contextos e circunstâncias (Peruzzo, 2009, p. 57).

Com base nas reflexões acima e considerando a perspectiva da própria denominação que os sujeitos da Rede Justiça nos Trilhos nos apresentam, como sendo uma articulação de comunidades e movimentos sociais atingidos pela Vale S.A., investimos na noção de comunidades para avançarmos no entendimento das ações de comunicação cidadã da Justiça nos Trilhos. Seria contraditório partir de uma nominação atribuída por nós para depois buscar entender as formas de organizações e articulações comunicativas da Rede, o caminho é inverso, são os próprios sujeitos sociais que evidenciam uma necessidade de refletir sobre a noção de comunidade, já que a Rede se caracteriza como tal.

Essa reflexão é necessária para pensarmos as comunidades como espaços plurais construídos por sujeitos sociais. Nos leva a entender as comunidades como lugares de produção de conhecimentos, cultura e política, essenciais para a construção de diálogos, embates e práticas cidadãs.

\section{Justiça nos Trilhos: articulações de comunidades em defesa da cidadania}

Com a compreensão das conjunturas política e social que envolvem as atividades de mineração, a Rede Justiça nos Trilhos se tornou uma articulação de comunidades, movimentos sociais, sindicatos, associações, entidades, grupos de pesquisa, dentre outros. Em sua página do site está exposta a seguinte mensagem, que registra as motivações para a agregação de diferentes atores: 
Se hoje nos unimos, é porque já conhecemos de perto o que existe para além da propaganda da Vale. Se nos articulamos, trocamos experiências e lutamos em conjunto, é porque percebemos que por detrás do discurso da empresa está a sua agressividade e seu poder destrutivo. Sabemos, por exemplo, que o papo de "sustentabilidade" tenta esconder os irreversíveis impactos causados ao meio ambiente; que a história de "responsabilidade social" é contada para ocultar o desrespeito aos direitos das comunidades atingidas pelos empreendimentos da Vale; que a divulgação da imagem de funcionários satisfeitos não apaga o desrespeito a leis trabalhistas nem a intransigência e a arrogância no trato com trabalhadores sindicalizados (Justiça nos Trilhos, 2017b).

A descrição “quem somos”, apresentada no site da Rede Justiça nos Trilhos expõe a diversidade dos atores sociais envolvidos no contexto da mineração na Amazônia e em outros países onde a Vale S.A. atua; os fatores que os unem no reconhecimento e defesa de direitos, bem como a identificação dos conflitos causados pela mineradora.

Os estudos de Freire (1983) se tornaram importantes para as nossas reflexões, já que estamos falando de um contexto permeado por desigualdades e opressões em comunidades tradicionais, populares e periféricas. Mesmo estando em um período histórico diferente daquele em que as obras do educador foram escritas, acreditamos na sua relevância para entender nosso universo, hoje, e para nos lançarmos ao desafio da crítica social.

Freire (1983) defende a comunicação como diálogo, uma ação construída entre sujeitos ao se conhecerem. Segundo o autor, o encontro é o eixo central para a realização do diálogo, o que dá sentido à existência dos sujeitos no mundo. Ao se caracterizar como uma rede de atores diversificados que busca romper com o silenciamento de vozes, com o apagamento de culturas e modos de vidas, a Rede Justiça nos Trilhos se aproxima das reflexões de Paulo Freire.

Ele defende o ato de comunicar como uma ação praticada a partir do encontro de sujeitos que buscam marcar "a significação dos significados". Assim, a comunicação estabelece um ideal de pertencimento a um espaço entre sujeitos, uma reciprocidade entre eles e a capacidade de lutarem para serem ouvidos diante de contextos de dominação e hegemonia.

Uma concepção humanista da comunicação também é defendida por Dominique Wolton (2010), que confere complexidade, assim como Freire, ao modo de pensar a comunicação, "tendo a troca como horizonte de toda experiência humana e social" (Wolton, 2010, p. 20). Reforçando o nosso posicionamento, ele também afirma que sua compreensão de comunicação tem a ver com tempo, respeito e confiança. Portanto, pensamos em comunicação como relação de troca, de confiança, de conflito, de respeito, de afeto, de amor, de laços, de aprendizagem e de tensões.

Por meio da Rede Justiça nos Trilhos os impactos diários provocados pela exploração mineral sobre as vidas das pessoas são denunciados, enfatizando modos de vida e as transformações na rotina de centenas de comunidades 
advindas com o Programa Grande Carajás nos estados do Maranhão e Pará. São ações e reflexões cidadãs sobre as suas realidades.

De acordo com a Rede, "de 2010 até 2017 ocorreram 39 mortes por atropelamentos ao longo de toda a ferrovia" (Justiça nos Trilhos, 2018, p. 6). Dados que justificam a ineficiência das passagens construídas pela mineradora nas comunidades e a falta de responsabilidade com a segurança das pessoas afetadas pela EFC. Esses registros ainda podem ser maiores, já que muitos acidentes não são contabilizados oficialmente.

Com a implantação da Estrada de Ferro Carajás, as comunidades são impedidas de ir e vir nos horários determinados pelas suas necessidades, e muitas vezes têm que esperar o horário do trem para se deslocar de um lugar a outro. Assim, direitos violados tornam-se práticas cotidianas adicionadas à normalidade dessas comunidades.

As práticas comunicativas da Rede Justiça nos Trilhos ampliam a cidadania na medida em que eles reconhecem uma série de impactos negativos implantados de forma hegemônica sobre os seus territórios e passam a lutar por melhores condições de vida. Segundo Peruzzo (2005, p. 13), com isso eles também colaboram para a transformação social de importantes segmentos da população.

Interessante notar que incorporam ainda a noção de dever de cidadania, pois tais organizações coletivas se vêm imbuídas do propósito de contribuir para a melhoria das condições de existência de segmentos populacionais excluídos, em geral visando suprir carências que o poder público não consegue atender, ou não quer atender (Peruzzo, 2005, p. 13).

A característica da luta coletiva, do valor da agregação entre diferentes pessoas torna-se essencial diante das estratégias utilizadas pela empresa Vale S.A. Os atores que estão à frente das organizações e dos movimentos não são capazes de resolver todos os problemas, mas o ambiente mobilizador que se forma já é um resultado positivo. É o que pode ser exemplificado pelas notícias em destaque no site da Rede Justiça nos Trilhos. 
Figura 2 - Notícias em destaque no site da Rede Justiça nos Trilhos em o8 set. 2018

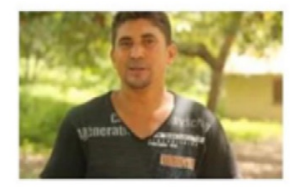

Trem da Vale atropela e mata lavrador em Buriticupu

O atropelamento ocorreu na comunidade Centro dos Farias zona rural do municipio Por volta das $21 \mathrm{~h}$, do dia 02 de malo, ot trem de minerio da Vale S.A, que fazia o trajetto Carajass Săo Luis. atropelou o lavrador Antonio Batista Farias, de 38 anos, que devido ao impacto morreu ainda no

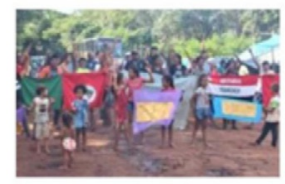

Comunidades de Açailândia protestam e fazem valer seus direitos

O protesto durou 14 dias e teve seu fim após as comunidades terem suas pautas atendidas

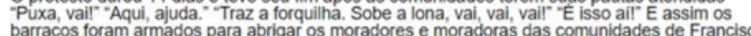
barracos foram armados para abrigar os moradores e morad
Romåo, Joăo do Vale, Agroplanatio, Boa Esperança [...]

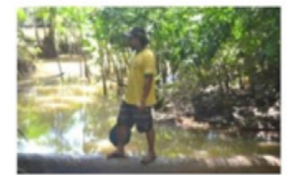

Hydro polui Rio Murucupi e tira direitos dos moradores de Barcarena

"Eu aprendi a nadar sem medo no Rio [Murucupi]. Meu vó me jogava e eu voltava, ele me jogava de novo e eu nadava", conta entusiasmada Agata, de oito anos., Ela e filiha de uma das 270
famillas de quilombolas da comunidade Gibrié de Săo Lourenco, em Barcarena (municiplo lamillas de quiliomboras da Comunidaace Gibrie
localizado no nordeste do Para), aftetacas [...]

Fonte: Justiça nos Trilhos, 2017a.

Segundo Mouffe (2015), a existência de uma natureza coletiva é importante para a construção de uma democracia radical que vai além do ideal de consenso e busca um confronto democrático. Essa "natureza de identidades coletivas" defendida por Mouffe (2015) abre precedentes para as relações em redes construídas no âmbito das comunidades e movimentos sociais atingidos pela Vale S.A. na Amazônia.

O trabalho da Justiça nos Trilhos se fortaleceu em 2009 com a participação no Fórum Social Mundial, uma rede de atores que comungam de interesses e características. E nesse sentido podemos apontar a participação da Rede em movimentos nacionais e internacionais como a Articulação Internacional das Atingidas e dos Atingidos pela Vale, Rede Brasileira de Justiça Ambiental, Observatorio de Conflictos Mineros em América Latina, dentre outros (Justiça nos Trilhos, 2018).

Um dos articuladores ${ }^{1}$ da Justiça nos Trilhos nos descreveu que as relações em redes, sejam locais, regionais, sejam globais, sempre estiveram presentes nas estratégias da Rede, já que lidam com uma empresa que se define como transnacional. A partir de seus depoimentos, consideramos que se trata de um trabalho processual, que amadurece conforme o crescimento da organização coletiva, das mudanças de reações dos "adversários" e do aproveitamento de oportunidades. Uma dessas oportunidades foi o Fórum Social Mundial, em 2009 .

1 Não mencionamos nomes para proteger a identidade das pessoas que fazem parte da rede. 
As ações de comunicação cidadã em redes também fortalecem instrumentos importantes para o acompanhamento de casos mais complexos que envolvem empresas e populações afetadas, como por exemplo: espionagem em organizações e movimentos sociais, assassinatos de lideranças comunitárias e defensores de direitos humanos, chacinas, entre outros. Muitas ações de comunicação da Rede Justiça nos Trilhos alertam para esse sentido de denúncia e proteção às vítimas.

Comprovadamente, a espionagem já fez parte das ações da Vale S.A. e foi realizada por meio de uma área intitulada "Vigilância e Inteligência", para aumentar o poder de dominação e controle sobre os indivíduos que não pactuam com as medidas da empresa, uma espécie de "laboratório de poder" (Foucault, 1987, p. 169). Denúncias mostraram um complexo sistema de espionagem que realizava escutas telefônicas sem autorização e conhecimento de funcionários e pessoas externas à própria empresa, como jornalistas e integrantes de movimentos sociais.

O sistema de espionagem da Vale S.A. também promovia a infiltração de pessoas (ligadas à empresa) em movimentos sociais e em comunidades. Esses fatos vieram a público durante o ano de 2013, por um ex-funcionário da empresa e constam em denúncias registradas no Relatório de Insustentabilidade da Vale, divulgado em 2015, pela Articulação Internacional das Atingidas e Atingidos pela Vale:

Em março de 2013, um ex-funcionário da Vale denunciou, ao Ministério Público e ao Senado Federal, o funcionamento da área de vigilância e inteligência da empresa. As informações revelam infiltração nos Movimentos dos Trabalhadores Rurais sem Terra (MST-RJ), no Assentamento Palmares (Pará), na rede Justiça nos Trilhos (MA-PA), na Prefeitura de Parauapebas (PA), na Câmara de Vereadores de Anchieta (ES) (Articulação Internacional dos Atingidos pela Vale, 2015).

Para dar visibilidade aos problemas vivenciados ao longo do Corredor de Carajás a Rede Justiça nos Trilhos, em parceria com diversos movimentos e organizações promovem eventos denominados de "Caravanas". As caravanas reúnem pesquisadores, moradores de comunidades atingidas pela Vale e jornalistas, e realiza visitas a esses lugares, como nos assentamentos mencionados. Nesses espaços ocorrem trocas e diálogos de gerações, entre culturas e diferentes modos de vidas. São processos comunicativos que fortalecem a organização comunitária.

É nesse sentido que abordamos as motivações que ocasionaram o nascimento da articulação comunitária e as suas formas de lutas e resistências no contexto da mineração na Amazônia brasileira com as práticas comunicativas de cidadania da Rede Justiça nos Trilhos. 


\title{
5. Considerações
}

Com base na exposição até aqui apresentada acreditamos que a Rede Justiça nos Trilhos atua com a comunicação cidadã na perspectiva de empoderar os sujeitos para o reconhecimento e a defesa de direitos, para gerar transformações e agregar relações entre diferentes atores sociais. A Rede representa uma articulação de comunidades e movimentos sociais que busca, pela comunicação cidadã, não só denunciar conflitos e impactos negativos, mas ter uma vivência baseada em processos de educação, com o envolvimento das comunidades. Nesse sentido explica Peruzzo (2005).

\begin{abstract}
A participação popular nas experiências mais avançadas de comunicação comunitária representa um avanço significativo na democracia comunicacional. Ela é essencial das organizações populares porque pode se constituir na diferença que ajuda a ampliar o exercício da cidadania. A comunicação comunitária tem o potencial de contribuir para a ampliação da cidadania não só pelos conteúdos crítico-denunciativo-reivindicatórios e anunciativos de uma nova sociedade, mas pelo processo de fazer comunicação. Há uma relação dinâmica entre comunicação e educação que merece ser analisada (Peruzzo, 2005, p. 16).
\end{abstract}

As características da ação coletiva cidadã observadas pelas práticas comunicativas da Justiça nos Trilhos com as comunidades e movimentos sociais afetados pela Vale S.A, possibilitam uma organização de tais atores que passam a aproximar suas formas de resistências e enfrentamento aos impactos provocados pela mineradora Vale S.A. nos territórios. São redes de atingidas e atingidos que exercem a busca por direitos e ampliam ações cidadãs.

As lutas e resistências identificadas nos contextos da exploração mineral na Amazônia brasileira são relatados com a presença de características já pontuadas pelos teóricos mencionados neste artigo: a pluralidade, o encontro, o diálogo, a troca de saberes e a partilha de experiência. Essas ações são responsáveis por conquistas e reconhecimentos de direitos que são adquiridos para além de comunidades específicas, mas de um conjunto de atores.

A identificação da mineradora Vale S.A. como um adversário reforçou os estudos mencionados por Mouffe (2003) que aborda a busca por uma democracia radical baseada nas relações entre adversários e não inimigos. Uma questão que identificamos nos modos de atuações da Justiça nos Trilhos, caracterizados pelo diálogo, a conversa, e baseados em um posicionamento crítico e contestador. Manifestações que objetivam mudar não somente as realidades das comunidades atingidas pela Vale S.A., mas também o modo de atuar da própria mineradora.

Com isso, as abordagens teórico-metodológicas dos autores mencionados neste estudo nos possibilitam considerar que a Rede Justiça nos Trilhos tem uma história de busca pela visibilização de comunidades impactadas pela Vale S.A. na Amazônia brasileira, de relações com movimentos e atores sociais individuais diversos, de uso da comunicação como processo de construção de saberes, 
reconhecimentos e construção de redes comunicativas de comunidades em âmbito local, nacional e internacional.

\section{Referências bibliográficas}

Articulação Internacional dos Atingidos pela Vale (2015). Relatório de Insustentabilidade da Vale 2015. [S.l.]: Articulação Internacional dos Atingidos pela Vale. Disponível em: https://goo.gl/zwrVZw

Avritzer, L. \& Lyyra, T. (1994). Movimentos sociais, renovação cultural e o papel do conhecimento: Entrevista de Alberto Melucci a Leonardo Avritzer e Timo Lyyra. Novos Estudos, (40), 152-166.

Castells, M. (2013). Redes de indignação e esperança: movimentos sociais na era da internet. Rio de Janeiro: Zahar.

Castells, M. (2015). O poder da comunicação. Rio de Janeiro: Paz e Terra.

Freire, P. (1983). Comunicação ou extensão? Rio de Janeiro: Paz e Terra.

Foucault, M. (1987). Vigiar e punir: história da violência nas prisões. Petrópolis: Vozes.

Gohn, M. G. (2013). Movimentos sociais e redes de mobilizações civis no Brasil contemporâneo. Petrópolis: Vozes.

Justiça nos Trilhos (2017a). Justiça nos Trilhos. Disponível em: https://goo.gl/DCpWLk

Justiça nos Trilhos (2017b). Quem somos. Justiça nos Trilhos. Disponível em: https://goo. $\mathrm{gl} / 4 \mathrm{z} 6 \mathrm{SoA}$

Justiça nos Trilhos (2018). Quanto vale a vida? Dados sobre atropelamento na Estrada de Ferro Carajás. Açailândia: Justiça nos Trilhos. Disponível em: https://goo.gl/HCdCEn

Melucci, A. (1989). Um objetivo para os movimentos sociais? Lua Nova, (17), 49-66.

Mouffe, C. (2003). Democracia, cidadania e a questão do pluralismo. Política e Sociedade, (3), 11-26.

Mouffe, C. (2015). Sobre o político. São Paulo: Martins Fontes.

Peruzzo, C. (2005). Direito à comunicação comunitária, participação popular e cidadania. Revista Latinoamericana de Ciencias de la Comunicación, 2(3), 18-41.

Peruzzo, C. (2009). Conceitos de comunicação popular, alternativa e comunitária revisitados e as reelaborações no setor. ECO-Pós, 12(2), 46-61.

Pinsky, J. \& Pinsky, C. B.(Org.). (2013). História da Cidadania (6 $6^{\text {a }}$ ed.). São Paulo: Contexto.

Santos, B. S. (2013). Pela mão de Alice. O social e o político na pós-modernidade. São Paulo: Cortez.

Touraine, A. (1989). Os novos conflitos sociais: para evitar mal-entendidos. Lua Nova, (17), 5-18.

Wolton, D. (2010). Informar não é comunicar. Porto Alegre: Sulina. 
